\title{
Short-Term Rupture Studies of Zircaloy-4 and Nb-Modified Zircaloy-4 Tubing using Closed-End Internal Pressurization
}

\author{
Y. Zhou ${ }^{1) 2)}$, B. Devarajan ${ }^{133)}$ and K. L. Murty ${ }^{1)}$ \\ 1) North Carolina State University, Raleigh, NC 27695 USA \\ 2) Now at University of California, Berkeley, CA \\ 3) Now at Georgia Institute of Technology, Atlanta, GA
}

\begin{abstract}
Burst rupture properties of Zircaloy-4 and Nb-Modified Zircaloy-4 are investigated at temperatures ranging from $638 \mathrm{~K}$ to $843 \mathrm{~K}$ by internal pressurization of closed-end tubing samples. Various pressurization levels were imposed and rupture times were noted. The data enabled an evaluation of Larson-Miller parameter and the present experimental results on Zircaloy-4 were in excellent agreement with those reported in the literature. The effect of $1 \% \mathrm{Nb}$ addition to Zircaloy4 was studied since these materials are now known to resist long-time corrosion in water reactors and are thus considered for high burn-up applications. Negligible differences were noted in the rupture characteristics between the standard Zircaloy-4 and Nb-added Zircaloy-4.

In addition, a limited amount of testing was performed to charaterize the hoop creep behavior of these materials using a creep tester with hoop strain monitored in-situ by a Laser telemetric extensometer. Both the alloys followed an exponential stress variation of the creep-rate at high $\left(>10^{-3} \mathrm{E}\right)$ stresses. At very low stresses, viscous creep ( $\left.\mathrm{n}=1\right)$ was noted identifiable with Coble creep corresponding to small grain sized materials.
\end{abstract}

\section{INTRODUCTION}

One of the concerns on the feasibility of surface storage of spent fuel is the creep deformation of the cladding because of the residual heat and fission products following exposure to neutron irradiation in commercial nuclear plants. Blind extrapolation of short-term creep results to low stresses encountered during dry storage could lead to nonconservative estimates of the creep-rates, creep-strains and life-times due to the dominance of viscous creep mechanisms at these conditions. No systematic studies were made in characterizing these mechanisms particularly under biaxial internal pressurization that is relevant to in-reactor as well as dry storage conditions. Such data are needed not only on the proto-typical cladding but also on many of the advanced fuel cladding materials that the industry has been proposing for extended burn-up[1]. These include Nb-modified Zircaloys such as Zirlo ${ }^{\circledR}, \mathrm{V}$-added M- $4^{@}$, etc.

It is well known that one of the primary considerations for the feasibility of dry storage of spent fuel is the creep deformation due to internal pressure (in the absence of external pressure such as is encountered in reactor operation). Although during wet storage, the temperature of the fuel rods is at relatively low levels due to the contact with the pool water, during dry storage the clad temperature initially increases due to the relatively poor (decay) heat removal by inert gases. Under these circumstances, the creep deformation and/or rupture of the spent fuel is one of the degradation mechanisms. Many investigators[2-6] considered the following four factors : (i) stress corrosion cracking (SCC) / pellet cladding interaction (PCI)[6], (ii) Creep, (iii) Corrosion[7] and (iv) delayed hydrogen cracking (DHC). They all regarded creep to be the prime degradation mechanism, limiting the possible life during dry storage as well as dictating the maximum allowable temperature (MAT) in order to maintain the integrity of spent fuel.

In creep predictions, the creep behavior of the unirradiated Zircaloy is often used as a conservative approach since irradiated cladding will deform much less due to radiation hardening as long as the temperatures are less than around 400C above which radiation damage is expected to anneal out. Chin and Gilbert[3] made a detailed study by first considering the deformation mechanism map for Zircaloy based on theoretical considerations. As first pointed out by Ashby[8] for materials in general and Knorr and Notis[9] for Zircaloy, the underlying operating mechanisms at various combinations of temperature and stress can be pictorially visualized by delineating fields in the normalized stress $(\sigma / \mathrm{E}, \mathrm{E}$ is the elastic modulus) and temperature $\left(\mathrm{T} / \mathrm{T}_{\mathrm{M}}, \mathrm{T}_{\mathrm{M}}\right.$ is the melting point in $\mathrm{K}$ ) superimposed with iso-strain-rate contours. These maps are as accurate as the constants and parameters used in the various deformation models, and indicate grain boundary sliding (GBS) to be the rate controlling mechanism at the inert dry storage (IDS) conditions[3]; however, the parameters used were apparently based on theoretical models. While GBS is a probable underlying deformation mechanism, no evidence exists for such a mechanism to be operative in Zircaloys especially under internal pressurization ( $\alpha=\sigma_{\theta} / \sigma_{\mathrm{Z}}=2$ where $\sigma_{\theta}$ and $\sigma_{\mathrm{z}}$ are the hoop and axial stresses).

Chin and Gilbert[3] went further to construct similarly the fracture mechanism map based on Ashby from which they concluded that the IDS conditions correspond to diffusion controlled cavity growth (DCCG). Thus, they used the Raj and Ashby[10] model for DCCG fracture mechanism to predict the fracture life times for the given temperature-time variations during the IDS of fuel cladding. Unfortunately, Zircaloys are known to be resistant to cavity formation and there is no concrete evidence of grain boundary cavity formation in both unirradiated and irradiated Zircaloy. Keusseyan's[11] work is the only one that seems to show evidence for the cavity formation. Majority of the literature, 
however, clearly refutes any such cavity formation. Even high neutron radiation exposures do not seem to show any voids or cavities in Zircaloys unlike in SSs and other metals. Many investigators attempted in vein to find cavities and reported the so-called black-dot microstructures comprising dislocation loops[12]. Yoo[13] presented a model based on the anisotropy of Zircaloys to rationalize the absence of voids and cavities in Zircaloys. Based on the proposal by Chin and Gilbert[3], many investigators made detailed calculations assuming the predominance of DCCG. Pescatore et al[5] point out the probable inapplicability of this model based again on the lack of sufficient experimental evidence for cavities in deformed Zircaloys.

We report here some recent data obtained on internal pressurization rupture and creep tests on the standard Zircaloy4 as well as Nb-modified Zircaloy with composition very similar to Zirlo. These results will be used in predicting the rupture life of cladding during dry storage conditions. Pitfalls in blind extrapolation of the short-term test data to low stress conditions of relevance to dry storage will be pointed out.

\section{EXPERIMENTAL ASPECTS}

Zirconium alloys used in the study were received in the form of thin-walled tubing in the cold-worked stress-relief (CWSR) annealed condition. The outer diameter of the tubing is $9.525 \mathrm{~mm}(0.375$ ") with a wall thickness of $0.533 \mathrm{~mm}$ (0.021"), and the compositions of the alloys are tabulated in Table 1; Zircaloy-4 is referred to Zry and Nb-added Zircaloy is referred to as Nb-Zry.

Table 1. Chemical composition (w\%) of Zircaloy-4 and Nb-added Zircaloy

\begin{tabular}{|c|c|c|c|c|c|c|}
\hline Alloy & Sn & Fe & Cr & O & Nb & $\mathbf{Z r}$ \\
\hline Zircaloy-4 & 1.5 & 0.21 & 0.10 & 0.01 & 0.0 & Balance \\
\hline Nb-Zry & 1.5 & 0.21 & 0.10 & 0.01 & 1.0 & Balance \\
\hline
\end{tabular}

The materials exhibited elongated grain structure in the hoop $(\theta)$ and thickness (r) faces while very small (ASTM grain size of around 13) equiaxed grain structure in the transverse (z) surface typical of the stress-relief annealed tubing [14]. Prism (100) and basal (001) pole figures for Zry and Nb-Zry are included in Figure 1 and exhibit typical bimodal distribution of basal poles with peaks at $33^{\circ}$ and $28^{\circ}$ respectively for Zry and Nb-Zry. The prism pole distributions cluster around the z-axis with minor peaks at $30^{\circ}$ typical of CWSR materials.

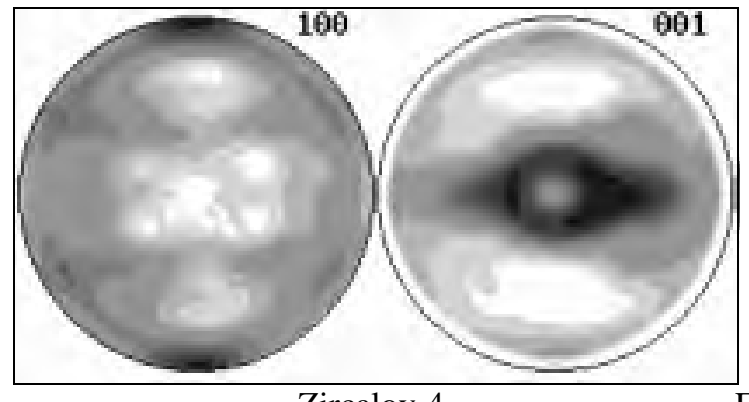

Zircaloy-4

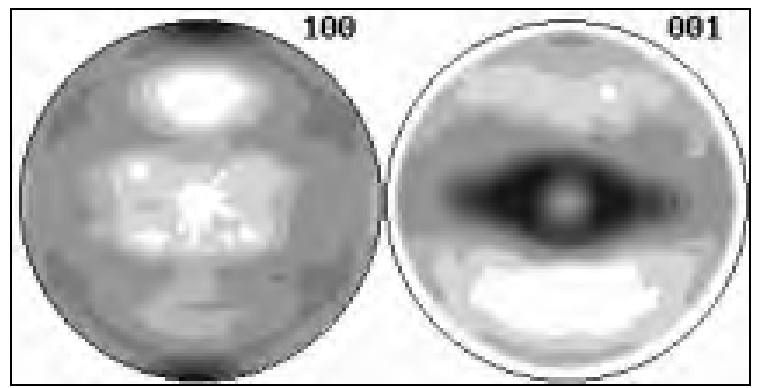

Nb-added Zircaloy

Burst tests were performed using a sustained gas pressurization system (ATS ${ }^{\circledR}$ model 1815) capable of gas pressurization to around $15 \mathrm{ksi}$. The system is equipped with an oven capable of reaching temperatures to around $600{ }^{\circ} \mathrm{C}$ and the temperatures could be maintained to $1^{\circ}$ in air. The internal pressurization was provided by compressed argon gas, and all test specimens were inserted with mandrels to reduce the air volume. The burst specimens were profiled for diametral changes along the tubing samples of around 6" using a noncontact telemetric Laser extensometer (Lasermike ${ }^{\circledR}$ model 60-03) so that the uniform hoop strains could be determined. Where possible, the total circumferential elongation to fracture was determined using a nonflexible string or tape.
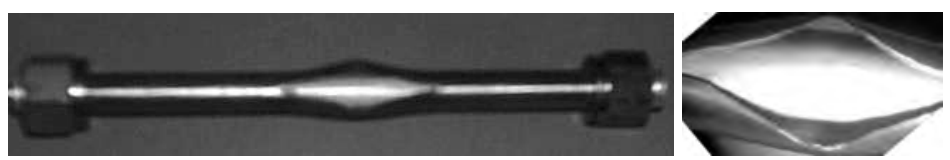

Figure 2

Burst specimen (638 K and $580 \mathrm{MPa}$ ) with the bust area close-up on right (uniform strain of $0.072 \%$ )

In addition to the sustained burst tests, biaxial creep tests under closed-end internal pressurization $\left(\sigma_{\theta}: \sigma_{\mathrm{z}}=2: 1\right)$ were performed to obtain the stress variation of steady-state creep-rates at a narrow range of temperatures from $723 \mathrm{~K}$ to 773 $\mathrm{K}$ at varied stresses from $40 \mathrm{MPa}$ to $100 \mathrm{MPa}$. A major objective is to characterize the transitional creep mechanisms in $\mathrm{Nb}-\mathrm{Zry}$ and compare them with the earlier results on Zry [14, 15]. The creep tests were performed on the biaxial creep machine (Figure 3 ) using the ATS ${ }^{@}$ load frame (model 2330) with a lever arm for axial loading; in these tests, no axial load is applied. The specimen was loaded by internally pressurizing with compressed inert argon and compressed air using the sustained pressurizing system that was also used for burst tests. The specimen temperature was maintained at the test temperature in an ATS 2961 series three-zone furnace such that the temperature variation of the sample was less 
than $\pm 1 \mathrm{~K}$. An additional thermocouple was provided which was in contact with the specimen to give a direct record of the actual specimen temperature. The hoop strains are continuously monitored using a telemetric Laser extensometer with the data recorded continuously on PC that displays in addition to time dependence of strain, the strain-rate variation also so that the onset of steady-state can be monitored. To minimize specimen to specimen scatter, isothermal creep tests were performed with internal pressures changed following steady-state at each test condition. A typical time-variation of hoop creep strain with sudden changes in the hoop stress is depicted in Figure 4 for a specimen tested at $723 \mathrm{~K}$. Thus, a few samples yield creep results at varied temperatures and stress levels.

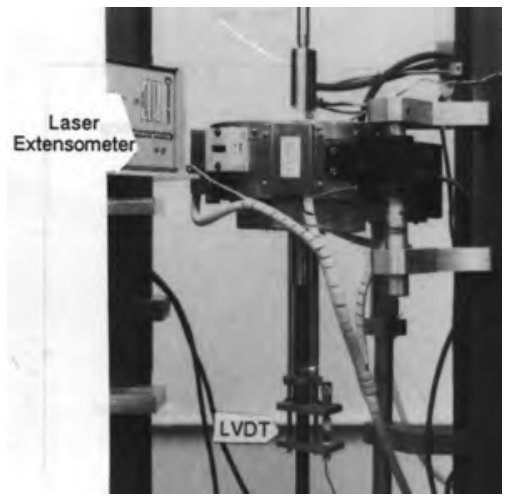

Figure 3

Biaxial creep set-up

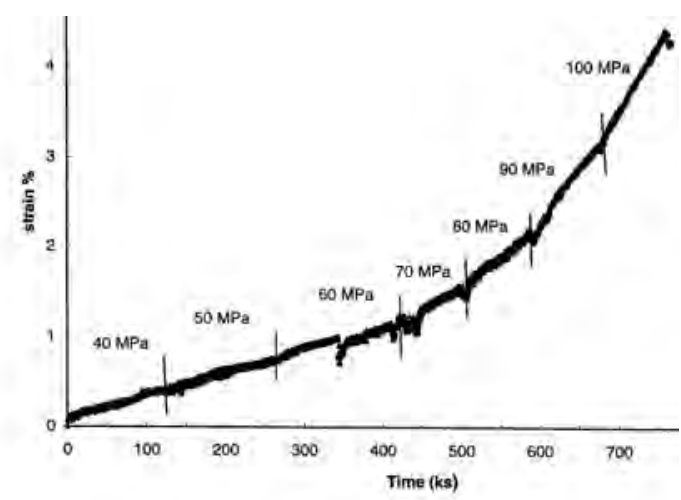

Figure 4

\section{EXPERIMENTAL RESULTS}

\section{Burst Properties}

The burst stresses are calculated using thin-wall formula,

$$
\sigma_{\theta}=\frac{\mathrm{pD}}{2 \mathrm{t}},
$$

where $\mathrm{p}$ is internal pressure, $\mathrm{D}$ the mean diameter and the thickness of the tubing. The stress variation of the rupture time at varied temperatures is shown in Figure 5. The corresponding (uniform) strain-rate is evaluated using the uniform circumferential elongation $(U C E)$ divided by the rupture time :

$$
\dot{\varepsilon}=\frac{\mathrm{UCE}}{\mathrm{t}_{\mathrm{r}}} .
$$

The UCE's were obtained from the laser profiles of the diameter variation along the tube length. These data seem to follow the same laws as obeyed by the steady-state creep-rates in closed-end internal pressurization tests. Figure 6 depicts the stress dependence of the strain-rate evaluated using equations 1 and 2, on a semi-log plot indicating exponential stress dependence as is expected at high $\left(>10^{-3} \mathrm{E}\right)$ stresses.

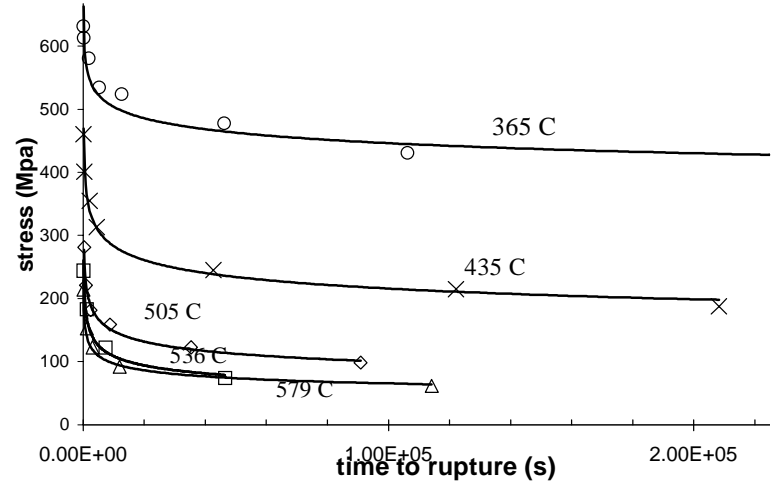

Figure 5

Effect of test temperature on stress vs rupture time

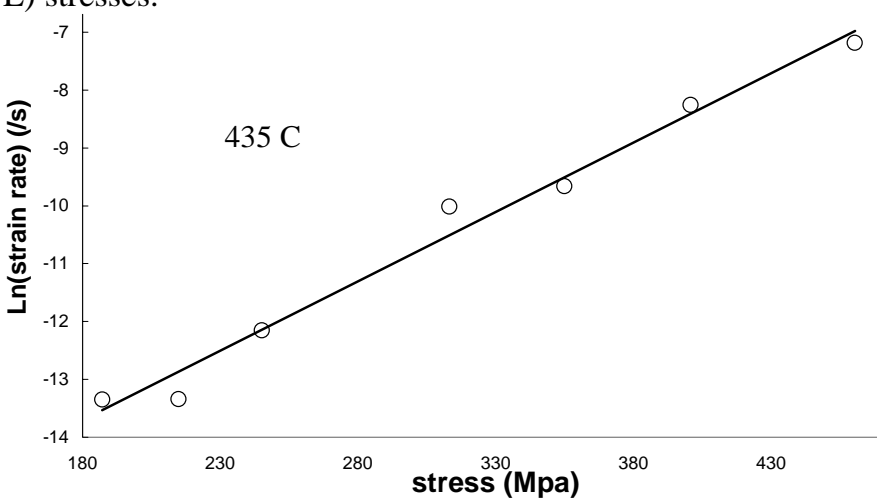

Figure 6

The experimental results are then fit to the creep-rate equation,

$$
\dot{\varepsilon}=\mathrm{A}^{\prime} \mathrm{f}(\sigma)=\mathrm{Ae}^{-\mathrm{Q} / \mathrm{RT}} \mathrm{e}^{\mathrm{B} \sigma},
$$

where $\mathrm{Q}$ is the activation energy for creep. Thus derived value for the activation energy was found to be $62.5 \pm 2$ $\mathrm{kCal} / \mathrm{mole}$ in excellent agreement with that for self diffusion [16] as well as from various creep results reported in the literature [17. These results imply that a sinh-function is valid so that at high stresses, an exponential stress dependence is noted while at stresses lower than around $\sigma<10^{-3} \mathrm{E}$, a power-law should be noted [17] : 


$$
\dot{\varepsilon}=\frac{\mathrm{CDEb}}{\mathrm{kT}}\left\{\sinh \left(\mathrm{B} \frac{\sigma}{\mathrm{E}}\right)\right\}^{\mathrm{n}}
$$

where $\mathrm{C}$ is a constant, $\mathrm{D}$ is the self-diffusion coefficient, temperature-dependent $\mathrm{E}$ the elastic modulus, $\mathrm{b}$ the Burger's vector, $\mathrm{k}$ the Boltzman constant and $\mathrm{T}$ is the test temperature. $\mathrm{B}$ in the above equation is a creep parameter related to the activation area for the underlying controlling mechanism and $\mathrm{n}$ is the stress exponent (around 5 for Zircaloys in this range of temperatures and stress levels). With the constants derived from the present set of data, we find,

$$
\dot{\varepsilon}=1.47 \times 10^{11} \mathrm{e}^{-31200 / \mathrm{T}} \frac{\mathrm{E}}{\mathrm{T}}\left\{\sinh \left(345 \frac{\sigma}{\mathrm{E}}\right)\right\}^{5} .
$$

The activation areas are derived, from the B values that seem to be weakly temperature dependent, using the equation 6 :

$$
\mathrm{A}^{*}=\frac{2 \mathrm{kT}}{\mathrm{b}}\left(\frac{\partial \ln \dot{\varepsilon}}{\partial \sigma}\right)_{\mathrm{T}}
$$

The values for $\mathrm{A}^{*}$ ranged from 13 to $19 \mathrm{~b}^{2}$ with a mean around $16 \mathrm{~b}^{2}$. Similar values $\left(20 \mathrm{~b}^{2}\right)$ were quoted earlier [18] at lower temperatures. These findings, namely the equivalence of the activation energies for creep and diffusion along with the relatively low value for $\mathrm{A}^{*}$ indicate that the climb of edge dislocations is the rate controlling process. In addition, recent work on dislocation microstructures in crept hep metals under biaxial loading do indicate the formation of distinct subgrains under these conditions [19].

\section{Rupture Time}

The rupture time is related to the steady-state strain-rate through the well-known Monkman-Grant relationship :

$$
\dot{\varepsilon} \mathrm{t}_{\mathrm{r}}=\kappa \text {, }
$$

where the constant $\kappa$ is a material parameter while the strain-rate incorporates both the stress and temperature effects. Figure 7 depicts the data from Figure 5 with the normalized rupture time $\left(\mathrm{t}_{\mathrm{r}} \mathrm{e}^{-\mathrm{Q} / \mathrm{RT}}\right)$ versus normalized stress $(\sigma / E)$ and we note that data at various temperatures coalesce into a single curve with distinct shape/slope. The low stress region is the power-law region while the high stress portion is exponential stress law region.

Often, stress rupture data are evaluated using the Larson-Miller parameter (LMP) defined by,

$$
\mathrm{LMP}=\mathrm{T}\left\{20+\log \left(\mathrm{t}_{\mathrm{r}}\right)\right\},
$$

where $\mathrm{T}$ is in $\mathrm{K}$ and the rupture time is in hours. Thus, data at different temperatures are normalized so that one can obtain the relation between the applied stress $(\sigma)$ and LMP; the test results on $\mathrm{Nb}$-Zry followed the following equation,

$$
\log (\sigma)=-1461 \times 10^{-4}(\mathrm{LMP})+4.52 .
$$

Data on Zry-4 also seem to follow the same trend,

$$
\log (\sigma)=-1.71 \times 10^{-4}(\mathrm{LMP})+4.91 .
$$

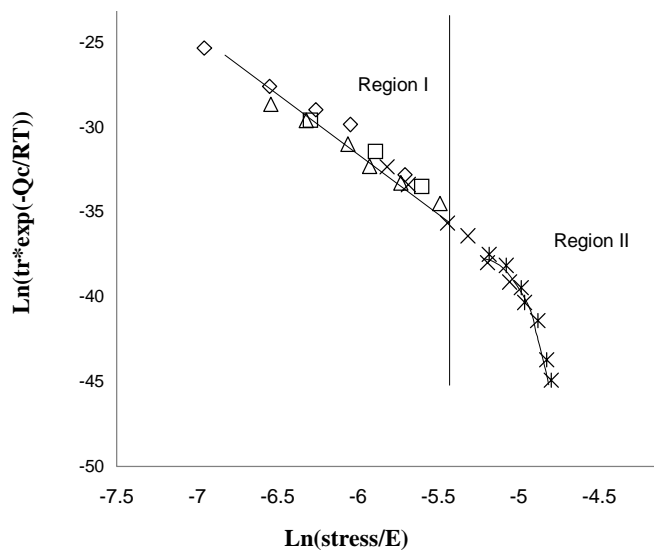

Figure 7

Semi-log plot of normalized rupture time and stress

Figure 8a includes data on both Nb-Zry and Zry-4 and we note negligible differences, if any, within the stress and temperature ranges studied here.

It is interesting to note that these results are in excellent agreement with those reported earlier by Mayuzumi and Onchi [20]; their data extend to far lower stresses or longer rupture times (Figure 8b). These data when extrapolated to low stresses and temperatures of concern in dry storage reveal rupture times of the order of 5,000 years[1].

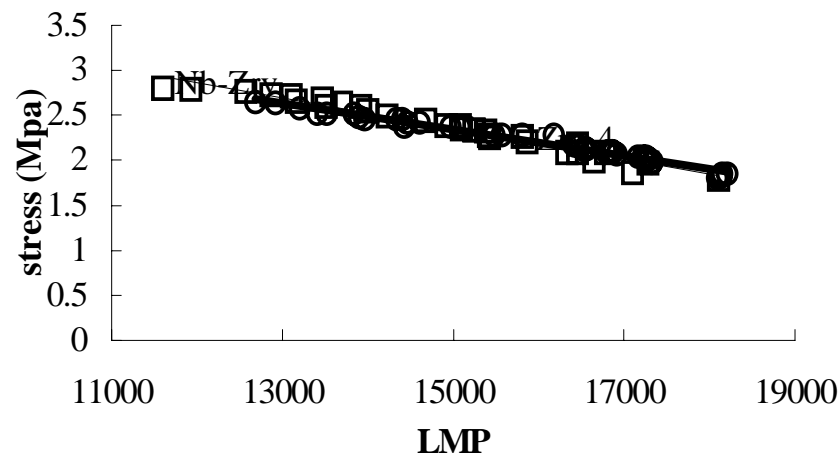

(a)

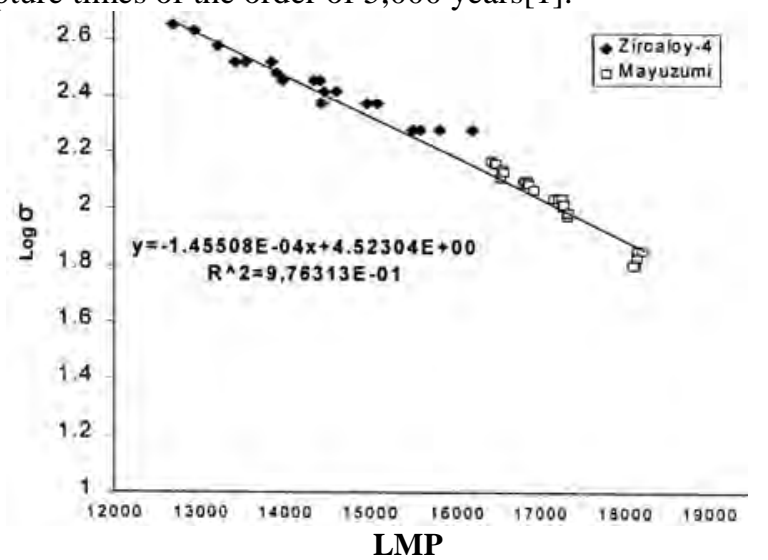

(b)

Current data on Zry-4 and Nb-Zry $\quad \sigma$ vs LMP Present results compared with literature [20] 


\section{Biaxial Creep of Nb-Zry}

As shown in Figure 4, the hoop creep curves were obtained at varied temperatures and stress levels using closed-end internally pressurized tubing samples. Hoop strains were monitored using the Laser telemetric extensometer while axial strains were recorded but for no further analyses; these strains, albeit are very small. From stress change tests at constant temperatures, the stress dependences of the steady-state or minimum creep-rates were evaluated. From double-log plots of steady-state creep-rate versus stress, we found 3 different regions depending on the stress level : at very low stresses, viscous creep with $\mathrm{n} \sim 1$; then $\mathrm{n} \sim 3$ corresponding to viscous glide of dislocations; at higher stresses, $\mathrm{n} \sim 5$ corresponding to dislocation climb and power-law break-down at very high stresses. It should be noted that tests at the low stresses were at the higher $(>500 \mathrm{C})$ temperatures only. Following values for the activation energies were found :

$$
26.18 \mathrm{kCal} / \mathrm{mole} \text { at low stresses when } \mathrm{n} \sim 1
$$

while

$$
58.36 \mathrm{kCal} / \mathrm{mole} \text { at higher stresses where } \mathrm{n}>3 \text {. }
$$

The higher value for large $\mathrm{n}$ is close to the self-diffusion value as seen earlier from the burst data. The lower value that is around $45 \%$ of the self-diffusion is identified with that for grain-boundary diffusion. All of these data at varied temperatures and stresses can be displayed as normalized strain-rate versus normalized stress :

$$
\frac{\dot{\varepsilon} \mathrm{kT}}{\mathrm{DEb}}=\mathrm{A}\left(\frac{\sigma}{\mathrm{E}}\right)^{\mathrm{n}},
$$

where D is the self-diffusion. Figure 9 is a double-log plot of these normalized strain-rates and stresses, and we note 4 distinct regimes as compiled in Table 2. The corresponding underlying deformation mechanism is also indicated. Similar results were reported by Murty et al [21] on a Nb-added Zircaloy sheet with very similar composition.

Table 2 Creep mechanisms (Biaxial 2:1 tests - Nb-Zry)

\begin{tabular}{|c|c|c|c|c|}
\hline Region & Stress range & $\mathrm{n}$ & $\mathrm{Q}_{\mathrm{c}}, \mathrm{kCal} / \mathrm{mole}$ & Deformation Mechanism \\
\hline I & $\sigma<6 \times 10^{-4} \mathrm{E}$ & 1 & 26.18 & Coble \\
\hline II & $6 \times 10^{-4} \mathrm{E}<\sigma<1 \times 10^{-3} \mathrm{E}$ & 3 & 58.36 & Viscous Glide \\
\hline III & $1 \times 10^{-3} \mathrm{E}<\sigma<4 \times 10^{-3} \mathrm{E}$ & 5 & 58.36 & Climb \\
\hline IV & $\sigma>4 \times 10^{-3} \mathrm{E}$ & $\exp (\mathrm{B} \sigma)$ & ---- & Power-law breakdown \\
\hline
\end{tabular}

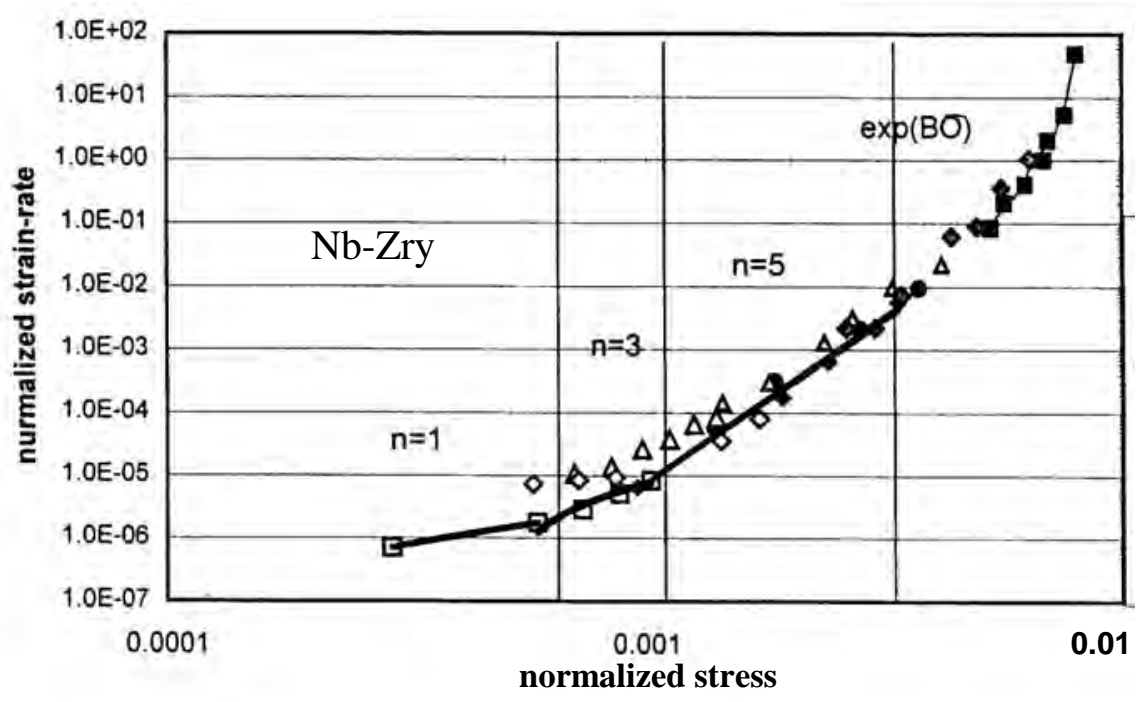

Figure 9

Normalized strain-rate versus normalized stress

It should be pointed out that similar biaxial creep tests on Zry- 4 did not exhibit $n=3$ range but $n=1$ at low stresses, $n$ about 5 at intermediate stresses while power-law breakdown at high stresses. These observations indicate that Zry behaves like a pure metal or class-II (or class-M) alloy while addition of $\mathrm{Nb}$ leads to alloy-class behavior (class-I or class-A type) where the dislocations are locked by the solute atoms leading to glide to be the dominant creep mechanism. The direct proportionality of the strain-rate to the applied stress in the low stress region is attributed to Coble creep as is usually observed in materials with small grain-size such as is used in the study (about $8 \mu \mathrm{m}$ ). With $\mathrm{Db}_{\mathrm{b}}$ corresponding to the grain-boundary diffusion, the creep-rates at $923 \mathrm{~K}$ were given by,

$$
\frac{\dot{\varepsilon} \mathrm{kT}}{\mathrm{D}_{\mathrm{b}} \mathrm{Eb}}=22\left(\frac{\mathrm{b}}{\mathrm{d}}\right)^{3}\left(\frac{\sigma}{\mathrm{E}}\right) \text {. }
$$


This is in agreement with the Coble creep model, which predicts a value of 50 for the prefactor.

In the intermediate stress range, the value of the stress exponent of 3 reveals that creep in this region is governed by the viscous glide of edge dislocations similar to creep in Class-A solid solution alloys such as $\mathrm{Al}-\mathrm{Mg}$ known as Weertman's microcreep[22]. Here, annihilation of dislocations by climb occurs, however, the locking of the moving dislocations lowers the rate of glide by solute atoms. Since the glide and climb processes occur in sequence, the slower controls creep. Thus in pure metals (and Class-M alloys), where the glide movement of the dislocations is not hindered [except for the resistance from Peierls hills], climb of edge dislocations becomes the rate controlling process. Whereas, in Class-A alloys, steady-state creep is governed by the rate of dislocation glide controlled by the rate of diffusion of solute atoms, and this creep mechanism is usually referred to as the viscous glide. The characteristic substructural feature usually noted in this region is the distinct absence of well developed subcell structures following deformation, and the electron microscopy studies of the samples crept in this region exhibited a uniform distribution of dislocations in the grain interior with no distinct subgrain boundaries[21].

At stresses higher than about $1 \times 10^{-3} \mathrm{E}$, the strain-rates increased with the applied stress much faster and the experimental strain-rates in this stress regime correlated with a stress exponent, $\mathrm{n}$, of $5 \pm 0.5$. This stress exponent is identifiable with that for cases where the climb of edge dislocations becomes the rate controlling mechanism as in pure metals and Class-M alloys. In particular, Thorpe and Smith[23] obtained for $\mathrm{Zr}-1 \% \mathrm{Nb}$ alloy values of 8.4 and 8.0 at temperatures 673 and $773 \mathrm{~K}$ respectively in a similar stress range (60-110 MPa). In addition, the electron microscopy work on crept samples revealed subgrain formation in the form of tilt and twist boundaries[22]. Thus, this high stress region is identified with the climb mechanism.

This transition from the viscous glide controlled creep (Class-A type) is believed to arise from the fact that as stress is increased, one reaches a critical stress above which the dislocations are freed from this locking and thus the rate limiting factor would be the annihilation of dislocations on parallel glide planes by climb as in pure metals and Class-M alloys. Murty estimated this critical stress $\left(\sigma_{c}\right)$ using the following expression[24],

$$
\sigma_{\mathrm{c}}=\frac{\mathrm{W}^{2} \mathrm{C}_{\mathrm{O}}}{2^{\delta} \mathrm{kTb}^{3}} \mathrm{E} .
$$

Here, $\mathrm{W}$ is the impurity-dislocation binding energy $(\sim 0.1$ to $0.25 \mathrm{eV}), \mathrm{C}_{\mathrm{o}}$ the solute concentration, and $\delta$ is a factor whose value depends on the nature of the impurity cloud ( $\sim 2$ for the size effect and $\sim 4$ for the elastic constant effect). Murty[24] estimated this critical stress to be $2 \times 10^{-3} \mathrm{E}$ [for $\mathrm{Al}-\mathrm{Mg}$ ] using the above expression. Despite some theoretical drawbacks, Weertman's dislocation pile-up and/or pill-box models are still regarded as the best known for explaining most of the observed experimental results[25]. As stress increases beyond about $4 \times 10^{-3} \mathrm{E}$, the experimental creep-rates increase much faster and the results may be correlated through an exponential function. It is known that at high stresses of this order or strain-rates greater than about $10^{9} \mathrm{D}$, power-law breakdown occurs. As per Zircaloy-4 cladding, these results could be described using a Sinh-function (Eqs. 4 and 5). Biaxial creep results on Zircaloy-4 tubing by Tanikella[26] revealed transitions similar to class-M alloys with dislocation climb at high stresses with Coble creep becoming dominant at low stresses. Hoop and axial creep-rates under equi-biaxial loading $\left(\sigma_{\theta}=\sigma_{\mathrm{Z}}\right)$ revealed the transition from stress exponent of 5 to viscous creep at low stresses. Similar findings were recently noted by Wang et al.[27] in uniaxial creep of Zircaloy cladding of different vintage.

These transitions in creep mechanisms clearly reveal the danger in blind extrapolation of the short-term high-stress data to low stresses and long times relevant to in-reactor conditions. In addition, anisotropy could be different in the various regimes with different stress sensitivities. Ravi et al.[28] studied the creep anisotropy in Zry-Nb sheet by considering the steady-state creep-rates along the rolling (RD) and transverse (TD) directions and showed that the creep anisotropy as defined by the ratio of the creep-rates along RD and TD decreased as the stress exponent decreased. Thus, one needs to consider these transitions along with varied creep anisotropies and the superimposed radiation exposure to predict the materials' behavior in-service.

\section{APPLICATION TO DRY STORAGE}

As mentioned before, dry storage of spent nuclear fuel is one option for interim storage until the fuel is reprocessed in the nuclear fuel cycle. During dry storage, the decay heat of the spent fuel is removed by conduction and convection of gaseous cooling media such as helium and nitrogen. Thus, temperature of spent fuel in dry storage is much higher than in wet storage. An example of the time variation of temperature during dry storage is shown in Figure 10[1], and some of the data are also included in Table 3. We note that the fuel rod temperature initially increases from $290{ }^{\circ} \mathrm{C}$ to around 330 ${ }^{\circ} \mathrm{C}$ and subsequently after about 10 years, it falls reaching $\sim 150{ }^{\circ} \mathrm{C}$ after 1000 years of storage/emplacement. Thus one needs to consider these variations (along with the corresponding changes in the stress due to deformation) in evaluating the accumulated total strains or tubing life. Creep deformation or rupture is the most probable degradation mechanism for Zircaloy-spent-fuel cladding, particularly in a postulated cooling device accident. In the creep prediction for long time waste storage, we need to calculate the total strain accumulated during storage time. This requires not only the stress and temperature variations of the steady-state creep-rate but also the time variation of creep strain during primary creep region. 
In the dislocation-climb dominated creep regimes, one could use the following equation to predict the accumulated creep strain[1],

$$
\varepsilon=\dot{\varepsilon}_{\mathrm{s}} \mathrm{t}+\frac{\kappa \varepsilon_{T} \dot{\varepsilon}_{s} t}{\varepsilon_{T}+\kappa \dot{\varepsilon}_{s} t} .
$$

In this equation, $\kappa$ is about 10 and $\varepsilon_{\mathrm{T}}$ is 0.008 . In region II where glide controlled creep of class-A type dominates, the extent of primary creep is known to be relatively short; appropriate values for the transient creep strain $\left(\varepsilon_{\mathrm{T}}\right)$ need to be developed. At very low stresses where viscous Coble creep dominates, essentially no primary creep is expected. The variation in the temperature during storage may be taken into account using Sherby-Dorn $\theta$-parameter[1]; however, a better approach is to evaluate the total strain as a sum of the piece-wise accumulated creep strains given by Eq. 8 or 10 using either strain-hardening or time-hardening rule. It was clearly demonstrated[1, 20] that strainhardening rule is more appropriate for Zircaloys. In the strain calculations, we used a constant hoop stress of 60 $\mathrm{MPa}$ although in reality as tubing expands, the internal pressure will slightly drop. Nevertheless, this approach will give a more conservative value for the accumulated strain.

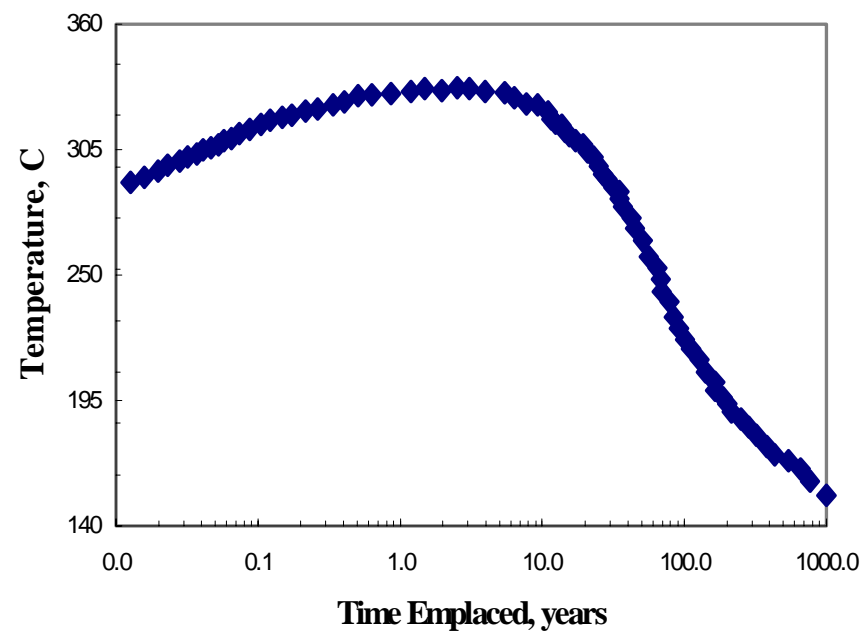

Figure 10

An Example of the Time Variation of

Fuel-Rod Temperature during IDS[1]

Table 3 summarizes results of calculations based on both the time-hardening and strain-hardening laws. At the end of 1000 years, the total accumulated strain for strain-hardening law is found to be $0.780 \%$ while that for timehardening law is $0.675 \%$. While the dislocation-dominant creep mechanism makes a significant contribution to creep at initial times, Coble creep becomes significant only during 1000-year period by which time, the clad temperatures decreases below $200^{\circ} \mathrm{C}$.

Table 3 Predicted hoop strains of Nb-Zry clad under dry-storage conditions

\begin{tabular}{|c|c|c|c|c|c|}
\hline $\begin{array}{c}\text { Time } \\
\text { years }\end{array}$ & $\begin{array}{c}\mathrm{T} \\
{ }^{\circ} \mathrm{C}\end{array}$ & $\begin{array}{c}\text { Coble } \\
\%\end{array}$ & $\begin{array}{c}\text { Dislocation } \\
\%\end{array}$ & $\begin{array}{c}\text { Total strain \% } \\
\text { Time-hardening }\end{array}$ & $\begin{array}{c}\text { Total strain \% } \\
\text { Strain-hardening }\end{array}$ \\
\hline 0.02 & 295.6 & $1.66 \mathrm{e}-4$ & $5.97 \mathrm{e}-6$ & $1.72 \mathrm{e}-4$ & $1.41 \mathrm{e}-4$ \\
\hline 1.19 & 330.4 & $3.12 \mathrm{e}-2$ & $2.72 \mathrm{e}-3$ & $3.39 \mathrm{e}-2$ & $3.40 \mathrm{e}-2$ \\
\hline 5.43 & 330.1 & $1.60 \mathrm{e}-1$ & $7.41 \mathrm{e}-3$ & $1.67 \mathrm{e}-1$ & $1.80 \mathrm{e}-1$ \\
\hline 10.94 & 321.7 & $2.94 \mathrm{e}-1$ & $1.00 \mathrm{e}-2$ & $3.04 \mathrm{e}-1$ & $3.38 \mathrm{e}-1$ \\
\hline 25.18 & 298.0 & $4.83 \mathrm{e}-1$ & $1.27 \mathrm{e}-2$ & $4.96 \mathrm{e}-1$ & $5.59 \mathrm{e}-1$ \\
\hline 51.31 & 265.2 & $5.98 \mathrm{e}-1$ & $1.39 \mathrm{e}-2$ & $6.12 \mathrm{e}-1$ & $6.96 \mathrm{e}-1$ \\
\hline 101.80 & 222.0 & $6.38 \mathrm{e}-1$ & $1.41 \mathrm{e}-2$ & $6.52 \mathrm{e}-1$ & $7.50 \mathrm{e}-1$ \\
\hline 200.50 & 193.5 & $6.50 \mathrm{e}-1$ & $1.41 \mathrm{e}-2$ & $6.64 \mathrm{e}-1$ & $7.67 \mathrm{e}-1$ \\
\hline 250.90 & 186.8 & $6.52 \mathrm{e}-1$ & $1.41 \mathrm{e}-2$ & $6.66 \mathrm{e}-1$ & $7.70 \mathrm{e}-1$ \\
\hline 540.80 & 168.7 & $6.58 \mathrm{e}-1$ & $1.41 \mathrm{e}-2$ & $6.72 \mathrm{e}-1$ & $7.77 \mathrm{e}-1$ \\
\hline 769.30 & 159.6 & $6.60 \mathrm{e}-1$ & $1.41 \mathrm{e}-2$ & $6.74 \mathrm{e}-1$ & $7.79 \mathrm{e}-1$ \\
\hline 993.70 & 153.5 & $6.61 \mathrm{e}-1$ & $1.41 \mathrm{e}-2$ & $6.75 \mathrm{e}-1$ & $7.80 \mathrm{e}-1$ \\
\hline
\end{tabular}

\section{LMP-Based Prediction}

Based on Larson-Miller Parameter, service life of $\mathrm{Nb}$-modified Zircaloy-4 can be predicted. Under the condition of dry storage of spent fuel, the highest temperature is $613 \mathrm{~K}\left(340{ }^{\circ} \mathrm{C}\right)$. Thus, the $\mathrm{P}$ is found as value 18103 . Using Eq. 8 , for $60 \mathrm{MPa}$ stress, the rupture is found to be $3.88 \times 10^{5}$ years. As we note from the creep results, transitions in creep mechanisms would strongly influence the LMP-stress relationship, and thus the long-time life predictions.

\section{EFFECT OF RADIATION EXPOSURE ON CREEP}

It is well known that radiation exposure results in hardening of materials and this is also true for Zircaloys[29, 30]. Limback and Andersson[31] used an irradiation hardening factor (IH) to find the creep-rate of irradiated cladding by dividing the creep-rate of unirradiated material by IH. This IH-factor was shown to depend on the fluence (or burnup) saturating at very high values. However, as Peehs et al[32] and Mayuzumi and Onchi[4] pointed out, using unirradiated clad creep information leads to conservative predictions (i.e., high strains) for IDS conditions. 


\section{REFERENCES}

1. K.L. Murty, "Internal Pressurization Creep of Thin-Walled Tubing of Zr-Alloys for Dry Storage Feasibility of Nuclear Spent Fuel," J of Metals, Sep. 2000, pp. 34-38.

2. M. Peehs and J. Fleisch, "LWR Spent Fuel Storage Behavior," J. Nucl. Mater., vol. 137, pp. 190-202 (1986).

3. B.A. Chin and E.R. Gilbert, "Prediction of Maximum Allowable Temperature for Dry Storage of Zircaloy-Clad Spent Fuel in Inert Atmosphere," Nucl. Tech., vol. 85, pp. 57-65 (1989).

4. M. Mayuzumi. and T. Onchi., "A Method to Evaluate the Maximum Allowable Temperature of Spent Fuel in Dry Storage During a Postulated Accident," Nucl. Tech., vol. 93, pp. 382-388 (1991).

5. C. Pescatore and M.G. Cowgill, "Temperature Limit Determination for the Inert Dry Storage of Spent Nuclear Fuel,” EPRI Report TR-103949, May, 1994.

6. K.L. Murty, "Stress Corrosion Cracking and Pellet Cladding Mechanical Interaction of Zircaloys - Application to LWRs," invited paper, to be published in Proceedings of $5^{\text {th }}$ National Convention on Corrosion, New Delhi, India, Nov. 99. (1999).

7. E.A. Preble, and K.L. Murty, "Influence of Intermetallic Precipitates on Corrosion Behavior of Zirconium Alloys," in Proceedings of International Conference on Corrosion (CORCON-97), Dec. 97, pp. 609-614 (1997)

8. M.F. Ashby, "A First Report on Deformation Mechanism Maps,” Acta Met., vol. 20, 887-894 (1972); see also, H.J. Frost and M.F. Ashby, "Deformation Mechanism Maps," Pergamon Press (1982).

9. D. B. Knorr and M. R. Notis, "Deformation Mechanism Mapping of $\alpha-Z r$ and Zirclaloy-2," J. Nucl. Mat., vol. 56, pp. 18-23 (1975).

10. R. Raj and M.F. Ashby, "Intergranular Fracture at Elevated Temperature," Acta Met., vol. 23, pp. 653-667 (1975).

11. R.L. Keusseyan, C.P. Hu and C.Y. Li, "Creep Damage in Zircaloy-4 at LWR Temperatures," J. Nucl. Mat., vol. 80, pp. 390-392 (1979).

12. A. Wolfenden and K. Farrel, "On the Question of Void Formation in Neutron Irradiated Zirconium," Scripta Met., vol. 6, pp. 127-129 (1972).

13. M.H. Yoo, "Suppression of Void Formation in Zirconium," in 'Zirconium in Nuclear Applications,' ASTM STP 551, pp. 292-307 (1974).

14. K. L. Murty, "Technological Applications of Crystallographic Textures of Zirconium Alloys," Materials Forum, Institute of Metals and Materials Australasia Ltd., 15 (1991) pp. 217 - 230.

15. Y. Wang, Effects of Temperature and Strain-Rate on Mechanical Anisotropy of Zircaloy Sheet, Ph.D. Thesis, North Carolina State University (1998).

16. V.S. Lyashenko, V.N. Bykor and L.V. Pavlinov, Phys. Met. Metal, vol. 40, 8 (1960).

17. K.L. Murty, G.S. Clevinger and T.P. Papazoglou, "Thermal Creep of Zircaloy-4 Cladding," in Proceedings of the 4th International Conference on STRUCTURAL MECHANICS in REACTOR TECHNOLOGY (1977) paper C3/4.

18. K. L. Murty, "Biaxial Creep of Zircaloy Cladding," Trans. IIM, 39, 357-368 (1986).

19. K. L. Murty, A. Paradkar and S. Nangalia, "Effect of Stress-Ratio on Biaxial Creep and Dislocation Microstructures in Recrystallized Ti3A12.5V Tubing," invited paper, to be published in Proceedings of TMS Symposium, Deformation, Processing and Properties of Structural Materials, E.M. Talef, C.K. Syn and D.R. Lesuer (eds), TMS, 2000, pp. 169-179.

20. M. Mayuzumi and T. Onchi., "Creep Deformation of an Unirradiated Zircaloy-4 Nuclear Fuel Cladding Tube Under Dry Storage Conditions," J. Nucl. Mater., vol. 171, pp. 381-388 (1990).

21. K.L. Murty, J. Ravi and Wiratmo, Nuclear Engineering and Design, 156 (1995) pp. 359 - 371.

22. J. Weertman, J Appl Phys, 28 (1957) 1185.

23. W.R. Thorpe and I.O. Smith, J Nucl Mater, 75 (1978) 209.

24. K.L. Murty, Scripta Met., $\underset{7}{\underline{1}}, 899$ (1973).

25. K.L. Murty and O. Kanert, J. Appl. Phys. 67 (1990) $2866-2872$.

26. B.V. Tanikella and K.L. Murty, "Transitions in Biaxial Creep of Zircaloy-4 Tubing," in $2^{\text {nd }}$ Asia-Pacific Symposium on Advances in Engineering Plasticity and its Applications (AEPA-2), Beijing (1994).

27. Y. Wang, Mathew M D and Murty K L, Metals and Materials, Vol. 4, No.4 (1998) 723.

28. J. Ravi, S.T. Mahmood and K.L. Murty, Nuclear Engineering and Design, 148 (1994) 1.

29. A.R. Causey, V. Fidleris, S.R. MacEwen and C.W. Schulte, "In-Reactor Deformation of Zr- $2.5 \mathrm{wt} \% \mathrm{Nb}$ Pressure Tubes," in 'Influence of Radiation on Material Properties: $13^{\text {th }}$ International Symposium (Part II),' ASTM STP 956, pp. 54-68 (1987).

30. V. Fidleris, "The Irradiation Creep and Growth Phenomena," J. Nucl. Mat., vol. 159, pp. 22-42 (1988).

31. M. Limback and T. Andersson, "A Model for Analysis of the Effect of Final Annealing on the In- and Out-Reactor Creep Behavior of Zircaloy Cladding," in 'Zirconium in the Nuclear Industry: Eleventh International Symposium,' ASTM STP 1295, pp. 448-468 (1996).

32. M. Peehs, G. Kaspar and E. Steinberg, "Experimentally Based Spent Fuel Dry Storage Performance Criteria," in $3^{\text {rd }}$ International Spent Fuel Storage Techniques Symposium and Workshop, vol. 1, S-316-S-331, US DOE-CONF86041/UC-85, pp. S-316 - S-331 (1986). 